\title{
Thermal food processing optimization: Algorithms and software
}

\author{
A. Abakarov , M. Nuñez
}

\begin{abstract}
A B S T R A C T
The algorithms and graphic user interface software package "OPT-PROx" are developed to meet food engineering needs related to canned food thermal processing simulation and optimization. The adaptive random search algorithm and its modification coupled with penalty function's approach, and the finite difference methods with cubic spline approximation are utilized by "OPT-PROx" package (http://tomakechoice.com/optprox/index.html). The diversity of thermal food processing optimization problems with different objectives and required constraints are solvable by developed software. The geometries supported by the "OPT-PROx" are the following: (1) cylinder, (2) rectangle, (3) sphere. The mean square error minimization principle is utilized in order to estimate the heat transfer coefficient of food to be heated under optimal condition. The developed user friendly dialogue and used numerical procedures makes the "OPT-PROx" software useful to food scientists in research and education, as well as to engineers involved in optimization of thermal food processing.
\end{abstract}

\section{Introduction}

Food engineering is the multidisciplinary field of applied sciences combined with the knowledge of product properties (Teixeira et al., 1969; Ramaswamy and Marcotte, 2005; Holdsworth and Simpson, 2007; Erdoğdu, 2008). Food engineering provides the technological knowledge transfer essential to the cost-effective production and commercialization of food products and services. In the development of food engineering, one of the many challenges is to employ state-of-art mathematical methods and based on these methods sophisticated dialogue software to develop new products and processes.

There has been significant progress in applying different optimization techniques in food engineering in the last few decades. Mainly, it became possible because of continuous advances in computer hardware and software allowed researchers to deal with these optimization techniques using computational resources. During the last four decades various optimization techniques have received great attention in food engineering (Holdsworth, 1985; Nakai, 1982; Erdoğdu, 2008). Holdsworth (1985) has presented a general review concerned with the mathematical methods for optimizing the effects of heat processing food products, which are reviewed in relation to microbial destruction, nutrient destruction, cooking value and loss of quality. A comparison of optimization techniques for food product and process development applications has been given by Nakai (1982). Banga et al. (2003) have presented the state of the art computer-aided optimization techniques used to improve food processing, especially focusing in recent developments using modern optimization techniques. Their potential for industrial applications was discussed in the light of several important examples. Finally, future trends and research needs are outlined. Erdoğdu (2008) presented a book that evaluates the potential uses and limitations of optimization techniques for food processing, including classical methods, artificial intelligencegenetic algorithms, multi-objective optimization procedures, global, structure, linear mixed integer optimization methods and computational fluid dynamics.

Thermal processing is one of the most important industrial technologies of food preservation in the manufacture of shelf stable canned foods (Teixeira, 1992). This topic is of great interest due to their numerous applications and potential economic importance (Ramaswamy and Marcotte, 2005; Holdsworth and Simpson, 2007; Erdoğdu, 2008). Mainly, thermal processing is concentrated on the following factors: final product safety and quality, total processing time and energy consumption. The diversity of thermal processing objectives impose different optimal requirements to sterilization processing, which can be determined analytically or by numerical procedures and based on these procedures sophisticated dialogue software. It is known, that well designed dialogue software significantly simplifies an engineering calculations process from its initial stage consisted of problem definition or (and) parameterization to the final stage consisted of realizing required 


\begin{tabular}{|c|c|c|c|}
\hline \multicolumn{4}{|c|}{ Nomenclature } \\
\hline$A$ & sufficiently large number & $r$ & radial cylindrical coordinate \\
\hline$a_{i}$ & cubic spline coefficients & $S$ & surface quality retention, $\%$ \\
\hline$b_{i}$ & cubic spline coefficients & $S^{d}$ & desired surface quality retention, \% \\
\hline$C_{\mathrm{av}}$ & volume average quality retention, $\%$ & $T$ & temperature, ${ }^{\circ} \mathrm{C}$ \\
\hline$c$ & cook or $C$ value, min & $T_{r t}$ & retort temperature, ${ }^{\circ} \mathrm{C}$ \\
\hline$C^{d}$ & desired cook or $C$ value, $\min$ & $T_{i n}$ & initial temperature, ${ }^{\circ} \mathrm{C}$ \\
\hline$C_{a v}^{d}$ & desired average quality retention, $\%$ & $T_{\text {low }}$ & lower limit of retort temperature, ${ }^{\circ} \mathrm{C}$ \\
\hline$c_{i}$ & cubic spline coefficients & $T_{\text {high }}$ & higher limit of retort temperature, ${ }^{\circ} \mathrm{C}$ \\
\hline \multirow[t]{2}{*}{$D_{\text {refc }}$} & time required to reduce the concentration of a nutrient & $T_{\text {reff }}$ & reference temperature, ${ }^{\circ} \mathrm{C}$ \\
\hline & by a factor of 10 at a certain temperature $T_{r e f c}$ & $T_{\text {refc }}$ & reference temperature, ${ }^{\circ} \mathrm{C}$ \\
\hline \multirow{2}{*}{$D_{r e f c}$} & time required to reduce the concentration of a nutrient & $T_{\text {refs }}$ & reference temperature, ${ }^{\circ} \mathrm{C}$ \\
\hline & by a factor of 10 at a certain temperature $T_{\text {refs }}$ & $T_{\text {refq }}$ & reference temperature, ${ }^{\circ} \mathrm{C}$ \\
\hline \multirow[t]{2}{*}{$D_{\text {reff }}$} & time required to reduce the concentration of a nutrient & $t$ & time, min \\
\hline & by a factor of 10 at a certain temperature $T_{\text {reff }}$ & $t_{\mathrm{f}}$ & final time, min \\
\hline \multirow[t]{2}{*}{$D_{\text {refq }}$} & time required to reduce the concentration of a nutrient & $t_{\text {left }}$ & left limit of process time, min \\
\hline & by a factor of 10 at a certain temperature $T_{\text {refq }}$ & $t_{\text {right }}$ & right limit of process time, min \\
\hline$d_{i}$ & cubic spline coefficients & $u$ & control vector \\
\hline$F$ & pedestal probability distribution & $V_{\mathrm{T}}$ & total volume, $\mathrm{m}^{3}$ \\
\hline$F_{0}$ & integrated lethality, min & $X$ & non-empty set of feasible decisions \\
\hline$F_{0}^{d}$ & required lethality, min & $x$ & vector of decision variables axial coordinate \\
\hline$f$ & cubic spline function & $x^{0}$ & center point of prospective domain $I$ \\
\hline$H$ & probability density for prospective sub-domain $I$ & $x_{r}^{i}$ & right bound of decision variable $x_{i}$ \\
\hline$h$ & probability density for non-prospective sub-domain $I$ & $x_{1}^{i}$ & left bound of decision variable $x_{i}$ \\
\hline$I$ & prospective sub-domain & $x^{*}$ & global optimal solution \\
\hline$N_{\mathrm{p}}$ & number of discretization points & $y$ & axial coordinate \\
\hline$N_{S}$ & number of random search iterations & $z$ & axial coordinate \\
\hline$n$ & number of decision variables & $z$ & axial coordinate \\
\hline$P_{1}$ & penalty function for lethality & $z_{\mathrm{f}}$ & temperature change needed to reduce the $\mathrm{D}$-value one \\
\hline$P_{2}$ & penalty function for average quality retention & & $\log$ cycle, ${ }^{\circ} \mathrm{C}$ \\
\hline$P_{3}$ & penalty function for surface quality retention & $z_{\mathrm{s}}$ & temperature change needed to reduce the $\mathrm{D}$-value one \\
\hline$P_{4}$ & penalty function for cook or $C$ value & & $\log$ cycle, ${ }^{\circ} \mathrm{C}$ \\
\hline$P_{5}$ & $\begin{array}{l}\text { penalty function used to hold the temperature profile } \\
T_{n}(t) \text { in the given range }\left[T_{\text {low }}, T_{\text {hight }}\right]\end{array}$ & $z_{\mathrm{s}}$ & $\begin{array}{l}\text { temperature change needed to reduce the } \mathrm{D} \text {-value one } \\
\log \text { cycle, }{ }^{\circ} \mathrm{C}\end{array}$ \\
\hline$p_{\min }$ & heuristic parameters of random search & $z_{\mathrm{q}}$ & temperature change needed to reduce the $\mathrm{D}$-value one \\
\hline$p^{5}$ & $\begin{array}{l}\text { assumed probability in step } s \text { where the optimal solu- } \\
\text { tion belongs to the prospective domain } I\end{array}$ & & $\log$ cycle, ${ }^{\circ} \mathrm{C}$ \\
\hline$q$ & half the width of prospective interval & Greek & ters \\
\hline$q_{\min }$ & heuristic parameters of random search & $\alpha$ & thermal diffusivity coefficient, $\mathrm{m}^{2} \mathrm{~s}^{-1}$ \\
\hline $\mathcal{R}$ & set of real numbers & $\Phi$ & objective or merit function \\
\hline$R$ & radius, $\mathrm{m}$ & $v$ & volume of the prospective domain $I$ \\
\hline$R_{1}$ & width, m & $\varepsilon$ & accuracy of the final result \\
\hline$R_{2}$ & height, $\mathrm{m}$ & $\xi$ & uniformly distributed random variable \\
\hline$R_{3}$ & depth, m & & \\
\hline
\end{tabular}

computations. Various types of computer software have been developed for simulation and optimization of the thermal food processing over the last few decades. The first computer program was developed in 1969 by Teixeira and others (Teixeira et al., 1969) to carry out a computer model for optimization of nutrient retention in thermal processing of conduction heated foods using a finite-difference technique. In 1975 Teixeira and others (Teixeira et al., 1975) have developed a computer program to show the advantages of a variable retort temperature (VRT) process over the traditional constant retort temperature (CRT) one. Hayakawa (1977) designed a group of programs to compute parametric values for thermal processing evaluation. Mishkin (1982) developed a computer program for modified Complex method to optimize a food dehydration process. Newman and Holdsworth (1989) presented a set of computer programs for determining the temperature distribution in objects of various geometric shapes. Silva et al. (1992) have developed a Pascal program to model and optimize heat sterilization of conduction-heated food. Banga et al. $(1991,1994)$ presented a new integrated controlled random search for dynamic systems (ICRS/DS) algorithm and based on this algorithm a computer program for optimization the thermal processing of conduction-heated food considering several objective functions. Sablani and Ramaswamy (1995) developed thermal process simulation program for canned foods under mechanical agitation. Chen and Ramaswamy (2007) developed a graphic user interface (GUI) software for thermal process calculation. It was designed to be applicable to different retort thermal processing systems such as constant and variable retort temperature processing with different types of foods such as solids, liquids, and liquids containing particles in containers of different shapes and sizes. Various software packages were developed by Erdogdu et al. $(1998,1999,2000)$, they are the following: (1) software, that calculates the optimum variable temperature profiles using the geometry options, objective functions, and constraints chosen by the user; (2) software to automate the calculation of heat transfer coefficient for irregular or regular (infinite and finite slab, infinite and finite cylinder, sphere) geometries; this software significantly facilitates and automates the calculation of heat transfer coefficient for 
various shapes and heating conditions; (3) windows-based software tool to predict internal temperatures, shrinkage, moisture loss, yield loss, and lethality for different sizes of shrimp, which made this program a useful tool in making cooking decisions. Sharma et al. (2011) have developed an Excel-based software for optimization the design of a falling-film evaporator system for milk concentration for multiple objectives; the Excel Worksheets were used by the authors for interfacing, calculation of particular objectives and constraints, while the multi-objective optimization algorithm was implemented inside the Excel Macro (Visual Basic for Application). Halder et al. (2011) have developed a software package that can simulate food safety by combining a physics-based model of food processes with the kinetics of microbiological and chemical changes to provide bacterial or chemicals amounts at any time and any location in the food during processing; the software package graphic user interface was built using Java Development Kit with the physics-based models solved in the background using COMSOL Multiphysics, a finite-element-based commercial modeling package. Balsa-Canto and Banga $(2010,2011)$ have presented a MATLAB based toolbox for advanced modeling and identification using global optimization (AMIGO). AMIGO is a powerful tool, which can be utilized for dynamic optimization of thermal food processing, including real-time optimization problems (Alonso et al., 2011).

The validation of computer simulation models is essential prior to actual use. The two following approaches were successfully performed to validate the software packages or computer programs mentioned above (Chen and Ramaswamy, 2007): (i) comparison of the developed models to the actual application, in other words, a developed model is evaluated on the basis of how well the model predictions match with the observed phenomena (Halder et al., 2011); (ii) comparison of the model with the output of other current models, which have been confirmed to be reliable (Chen and Ramaswamy, 2007). Since the retort thermal processing is a mature processing technology, several analytical theoretical models for heat penetration and the various formula's methods for process calculations have been developed and confirmed by volumes of research and practical applications (Chen and Ramaswamy, 2007).

Reference to the thermal processing optimization and simulation techniques and software, including commercial software packages, can be found in the following publications: Lund (1982), Holdsworth (1985), Chen and Ramaswamy (2007), Banga et al. (1991, 2003), Chazala (1998), Erdoğdu (2008), and Halder et al. (2011).

Therefore, the objective of this research consists of development a user-friendly GUI software package to meet such food engineering need as thermal food processing simulation and optimization.

\section{Material and methods}

\subsection{Heat transfer models for thermal sterilization of foods}

\subsubsection{Finite cylinder}

In the particular case of a cylindrical container with radius $R$ and height $2 L$, the mathematical model describing heat transfer by conduction is a mixed boundary problem, as follows (Teixeira et al., 1969):

$\frac{\partial T}{\partial t}=\alpha\left(\frac{\partial^{2} T}{\partial r^{2}}+\frac{1}{r} \frac{\partial T}{\partial r}+\frac{\partial^{2} T}{\partial z^{2}}\right)$

where $T$ is temperature, $t$ is time, $r$ and $z$ are radial and vertical locations within the container, and alpha $(\alpha)$ is the thermal diffusivity of the product.

The model has the following initial and boundary conditions (by symmetry):
$T(R, z, t)=T_{r t}(t)$,

$T(r, L, t)=T_{r t}(t)$,

$\frac{\partial T}{\partial r}(0, z, t)=0$

$\frac{\partial T}{\partial z}(r, 0, t)=0$,

$T(r, z, 0)=T_{\text {in }}$

where $T_{r t}(t), t \in\left[0, t_{f}\right]$ will be the retort temperature as a function of time, and $T_{\text {in }}$ is the initial temperature at $t=0$.

\subsubsection{Sphere}

The basic mathematical model for determining the temperature distribution in a spherical object of radius $R$ can be presented as follows (Erdogdu and Balaban, 2003b; Holdsworth and Simpson, 2007):

$\frac{\partial T}{\partial t}=\alpha\left(\frac{\partial^{2} T}{\partial r^{2}}+\frac{2}{r} \frac{\partial T}{\partial r}\right)$

subject to the following initial and boundary conditions (by symmetry):

$T(R, t)=T_{r t}(t)$,

$\frac{\partial T}{\partial r}(0, t)=0$,

$\frac{\partial T}{\partial z}(r, t)=0$,

$T(r, 0)=T_{\text {in }}$.

\subsubsection{Rectangular parallelepiped}

The mathematical model for determining the temperature distribution in a rectangular-shaped container of dimensions $2 R_{1} \times$ $2 R_{2} \times 2 R_{3}$ can be presented as follows (Luikov, 1968):

$\frac{\partial T}{\partial t}=\alpha\left(\frac{\partial^{2} T}{\partial x^{2}}+\frac{\partial^{2} T}{\partial y^{2}}+\frac{\partial^{2} T}{\partial z^{2}}\right)$

subject to the following initial and boundary conditions:

$T\left( \pm R_{1}, y, z, t\right)=T_{r t}(t)$,

$T\left(x, \pm R_{2}, z, t\right)=T_{r t}(t)$,

$T\left(x, y, \pm R_{3}, t\right)=T_{r t}(t)$

$T(x, y, z, 0)=T_{\text {in }}$.

\subsection{Problem statement for thermal sterilization of foods}

The lethality constraint can be specified as follows: (i) $F_{0}\left(t_{f}\right) \geqslant F_{0}^{d}$, where $F_{0}^{d}$ is the final required lethality and is calculated according to the following equation:

$F_{0}(t)=\int_{0}^{t_{f}} 10^{\frac{\left(T-T_{\text {reff }}\right)}{z_{f}}} d t$

where $T$ is the temperature at the critical point or cold spot, normally the geometric center of the container (in the case of conduction-heated canned foods), $T_{\text {reff }}$ is the reference temperature and $z_{f}$ is the thermal resistance of the microorganisms (in this case, $T_{\text {reff }}=121.11^{\circ} \mathrm{C}$ and $z_{f}=10^{\circ} \mathrm{C}$ ).

The quality retention constraint is specified as follows: (ii) $C_{a v}\left(t_{f} \geqslant C_{a v}^{d}\right)$, where $C_{a v}^{d}$ is the desired volume-average final quality retention value and is calculated as shown in the following equation (Holdsworth, 1985; Awuah et al., 2007):

$C_{a v}\left(t_{f}\right)=\frac{1}{V_{T}} \int_{0}^{V_{T}} \exp \left[-\frac{\ln 10}{D_{\text {refc }}} \int_{0}^{t_{f}} 10^{\frac{\left(T-T_{r e f f}\right)}{z_{C}}} d t\right] d V_{T}$ 
where $T_{\text {refc }}$ is the reference temperature, $z_{c}$ and $D_{\text {refc }}$ are kinetics of degradation of nutrients.

The surface retention is as follows (Holdsworth, 1985; Awuah et al., 2007)

$S\left(t_{f}\right)=\exp \left[-\frac{\ln 10}{D_{f e f s}} \int_{0}^{t_{f}} 10^{\frac{\left(T-T_{\text {refs }}\right)}{z_{\mathrm{s}}}} d t\right]$,

where $T_{r e f 5}$ is the reference temperature, $z_{5}$ and $D_{\text {refs }}$ are kinetics of degradation of nutrients, and the surface retention constraint can be specified as follows: (iii) $S\left(t_{f}\right) \geqslant S^{d}$, where $S^{d}$ is the desired final surface retention value.

Also a common relationship for estimating quality losses is the "Cook or C value" which was originally proposed by Mansfield (1962), and is calculated as shown in the following equation Holdsworth, 1985; Awuah et al., 2007):

$C\left(t_{f}\right)=\int_{0}^{t_{f}} 10^{\frac{\left(T-T_{\text {refq }}\right)}{z_{q}}} d t$

where $z_{q}$ and $T_{\text {refq }}$ represent the $z$-value and reference temperature for the most heat labile component. The $z$-value for cooking degradation, ranging from $25^{\circ} \mathrm{C}$ to $47^{\circ} \mathrm{C}$, corresponds to sensory attributes, texture softening, and color changes. The $z$-value of $33.1{ }^{\circ} \mathrm{C}$ and $T_{\text {refq }}$ equal to $100^{\circ} \mathrm{C}$ are often used to compute a cook value describing the overall quality loss (Lund, 1986; Wang et al., 2003). The cook value constraint is specified as follows: (iv) $C\left(t_{f}\right) \leqslant C^{d}$, where $C^{d}$ is the desired minimum final cook value.

The following types of single thermal process optimization problems were considered over the last few decades (Abakarov et al., 2009a):

(1) Find such a retort function, $T_{r t}(t), T_{\text {low }} \leqslant T_{r t}(t) \leqslant T_{\text {hight }}$, where the final quality retention $C_{a v}(t)$ is maximized, while the final process lethality, $F_{0}^{d}$, is held to a specified minimum (Teixeira et al., 1975; Silva, 1994a; Banga et al., 1991; Erdogdu and Balaban, 2002; Chen and Ramaswamy, 2002; García et al., 2005; Erdoğdu, 2008).

(2) Find such a retort function, $T_{r t}(t), T_{\text {low }} \leqslant T_{r t}(t) \leqslant T_{\text {hight }}$, where the surface quality retention $S(t)$ is maximized, while the final process lethality, $F_{0}^{d}$, is held to a specified minimum (Banga et al., 1991; Silva et al., 1994b; Noronha et al., 1996; Ansorena and Salvadori, 2011).

(3) Find a retort function, $T_{r t}(t), T_{\text {low }} \leqslant T_{r t}(t) \leqslant T_{\text {hight }}$, such that the final process time $t_{f}$ is minimized subject to the same lethality requirement above, while the quality retention must not fall beneath some specified minimum (Banga et al., 1991; Erdoğdu, 2008; Abakarov et al., 2009b);

(4) Find a retort function, $T_{r t}(t), T_{\text {low }} \leqslant T_{r t}(t) \leqslant T_{\text {hight }}$, where the cook value $S(t)$ is minimized, while the final process lethality, $F_{0}^{d}$, is held to a specified minimum (Silva, et al., 1992; Hendrickx et al., 1993; Chen and Ramaswamy, 2002);

(5) Find a retort function, $T_{r t}(t), T_{\text {low }} \leqslant T_{r t}(t) \leqslant T_{\text {hight }}$, such that the final process time $t_{f}$ is minimized subject to the same lethality requirement above, while the quality retention must not fall beneath some specified minimum, and energy consumption must not exceed a specified maximum; minimum and maximum values are computed at constant retort temperature profiles (Almonacid-Merino et al., 1993).

The thermal process optimization problem was also posed and solved as a multi-objective optimization problem. Erdogdu and Balaban (2003a) utilized the weighing and lexicographic ordering methods coupled with the modified complex method to determine the variable process temperature profile during thermal processing to maximize the volume average or surface retention of a nutrient in conduction heated foods of different geometries (a sphere and a finite cylinder). Sendín et al. (2004, 2010) described an efficient and robust multi-criteria optimization method which can be successfully applied to large dynamic systems, like those arising from the modeling of thermal processing of foods. The aim of the multicriteria optimization problem was to find the time-dependent temperature profile to simultaneously: (1) maximize the overall retention of a nutrient, (2) maximize the surface retention of a quality factor, and (3) minimize the total process time. Abakarov et al. (2009, 2011) utilized a multiobjective optimization and decision making technique for the thermal sterilization of packaged foods. The multiobjective optimization approach used in that study was based on the optimization of aggregating functions by an adaptive random search algorithm. The numerical results obtained for the multiobjective test problems and for the thermal processing problem showed that the proposed approach can be effectively used for solving multiobjective optimization problems arising in the food engineering field.

In the general case, the function $T_{r t}(t)$ over $t \in\left[0: t_{f}\right]$ can be parameterized using $N_{p}$ points, and during each time interval $t_{k}^{\prime}=\left[t_{k}, t_{k+1}\right), k \in 0:\left(N_{p}-1\right)$, the value of $T_{r \mathrm{r}}\left(t_{k}^{\prime}\right)$ remains constant at $u_{k}$ (Teixeira et al., 1975; Banga et al., 1991, 2003; García et al., 2005). However, in this case, the use of a cubic spline in approaching global optimization problems with random search technique can produce superior results over discrete step-wise functions (Simpson et al., 2008), mainly because the cubic spline approximation allows for significantly reducing the number of decision variables and therefore the necessary number of objective function computations to reach the global solution. Therefore, the approximation by the cubic spline was utilized in this study in order to find optimal VRT profiles.

In the general case, the single-thermal-process optimization problem utilizing the cubic spline approximation can be presented as (Abakarov et al., 2009a):

$$
\begin{aligned}
\Phi\left(u_{1}, u_{2}, \ldots, u_{N_{p}-1}, t_{f}\right) & =t_{f}+P_{1}+P_{2}+P_{3}+P_{4}+P_{5} \\
& \rightarrow \min , \quad t_{f} \in\left[t_{\text {left }} t_{\text {right }}\right],
\end{aligned}
$$

where $u_{i}, i \in 1:\left(N_{p}-1\right)$ are the control variables, $t_{\text {left }}$ and $t_{\text {right }}$ are the left and right limits of process time, respectively; $t_{\text {left }}$ and $t_{\text {right }}$ can be obtained from the following expressions:

$$
\begin{aligned}
& F_{0}^{d}=\int_{0}^{t_{\text {right }}} 10^{\frac{\left(T_{\text {low }}-T_{\text {ref }}\right)}{z}} d t, \\
& F_{0}^{d}=\int_{0}^{t_{\text {left }}} 10^{\frac{\left(T_{\text {hight }}-T_{\text {ref }}\right)}{z}} d t,
\end{aligned}
$$

$P_{1}, P_{2}, P_{3}, P_{4}$ are the penalty functions for lethality, average quality retention, surface quality retention and cook value, respectively; the following expressions can be used as penalty functions (Abakarov et al., 2009a):

$$
\begin{aligned}
& P_{1}=\sum_{t=0}^{t_{f}} A \times\left(F_{0}^{d}-F_{0}(t)+\left|F_{0}^{d}-F_{0}(t)\right|\right), \\
& P_{2}=\sum_{t=0}^{t_{f}} A \times\left(C_{a v}^{d}-C_{a v}(t)+\left|C_{a v}^{d}-C_{a v}(t)\right|\right), \\
& P_{3}=\sum_{t=0}^{t_{f}} A \times\left(S^{d}-S(t)+\left|S^{d}-S(t)\right|\right), \\
& P_{4}=\sum_{t=0}^{t_{f}} A \times\left(C(t)-C^{d}+\left|C^{d}-C(t)\right|\right),
\end{aligned}
$$

where $A$ is a penalty parameter (Himmelblau, 1972), and $P_{5}$ is the penalty function that was used simultaneously with the cubic spline approximation in the search process in order to hold the autoclave temperature profile $T_{r t}(t)$ in the given range $\left[T_{\text {low }}, T_{\text {hight }}\right]$ (Abakarov et al., 2009a): 
$P_{5}=\sum_{t=0}^{t_{f}} A \times\left(\left|T_{\text {low }}-T_{r t}(t)\right|+\left|T_{\text {hight }}-T_{t t}(t)\right|+\left(T_{\text {low }}-T_{\text {hight }}\right)\right)$

The penalty parameter $A$ is normally taken as a large positive number in order to ensure that the magnitude of the penalty term is large relative to the magnitude of objective function (in this case the value $A=1000$ was used). For the candidate VRT profiles with no limit violation, the penalty function values become zero and the value of merit function (21) is equal to the objective function value. On the other hand, if there is any violation in the lower or upper limit of the decision variables, a corresponding penalty value based on the amount of violation is added to the objective function. Since, this penalty value is proportional to the distance to the feasible domain, the adaptive random search algorithm will lead to finding such solutions or VRT profiles that all the given constraints are satisfied.

\subsection{Cubic spline approximation}

The name spline comes from the thin flexible rod, called a spline, used by draftsmen to draw smooth curves through a series of discrete points (Hoffman, 2001). The spline is placed over the points and either weighted or pinned at each point. Due to the flexure properties of a flexible rod, the slope and curvature of the rod are continuous at each point. A smooth curve is then traced along the rod, yielding a spline curve. Given $n+1$ total points $x_{i}, i \in 1:(n+1)$, $\mathrm{n}$ intervals, and $n-1$ interior grid points, $x_{i}, i \in 1: n$. A cubic spline is to be fit to each interval. Thus,

$f_{i}(x)=a_{i}+b_{i} x+c_{i} x^{2}+d_{i} x^{3}, \quad i \in 1: n$,

defines the cubic spline in interval $i, x_{i} \leqslant x \leqslant x_{i+1}, i \in 1: n$. Since each cubic spline has four coefficients and there are n cubic splines, there are $4 n$ coefficients to be determined. Thus, $4 n$ boundary conditions, or constraints, must be available. In the cubic spline approach, the following constraints are applied.

(1) The function values, $f_{i}(x)=f_{i}, i \in 1: n$, must be the same in the two splines on either side of $x_{i}$ at all of the $(n-1)$ interior points. This constraint yields $2(n-1)$ conditions.

(2) The first derivative of the two splines on either side of point $x_{i}$ must be equal at all of the $(n-1)$ interior points. This constraint yields $(n-1)$ conditions.

(3) The second derivative of the two splines on either side of point $x_{i}$ must be equal at all of the $(n-1)$ interior points. This constraint yields $(n-1)$ conditions.

(4) The first and last spline must pass through the first (i.e., $x_{1}$ ) and last (i.e., $\left.x_{n+1}\right)$ points. That is $f_{1}\left(x_{1}\right)=f_{1}$ and $f_{n}\left(x_{n+1}\right)=f_{n+1}$. This constraint yields 2 conditions.

(5) The curvature $f^{\prime \prime}(x)$ must be specified at the first (i.e., $x_{1}$ ) and last (i.e., $\left.x_{n+1}\right)$ points. That is, $f_{1}^{\prime \prime}\left(x_{1}\right)=f_{1}^{\prime \prime}$ and $f_{n}^{\prime \prime}\left(x_{n+1}\right)=f_{n+1}^{\prime \prime}$. This constraint yields 2 conditions.

When all of the conditions given above are assembled, $4 n$ linear algebraic equations are obtained for the $4 n$ spline coefficients $a_{i}$,$b_{i}, c_{i}$, and $d_{i}, i \in 1: n$. This set of equations can be solved by Gauss elimination (Hoffman, 2001).

\subsection{Adaptive random search algorithm}

Let the global optimization problem be formulated as follows, in which some continuous objective function of a decision variable is to be minimized over a set of candidate decision variables:

$\Phi(x) \rightarrow \min _{x \in X}$

where: $X=[0,1]^{n} \subset \mathcal{R} \backslash$ is a non-empty set of feasible decisions (a proper subset of $\left.R^{n}\right), x=\left\langle x_{1}, x_{2}, \ldots, x_{n}\right\rangle \in X$ is a real $n$-vector decision
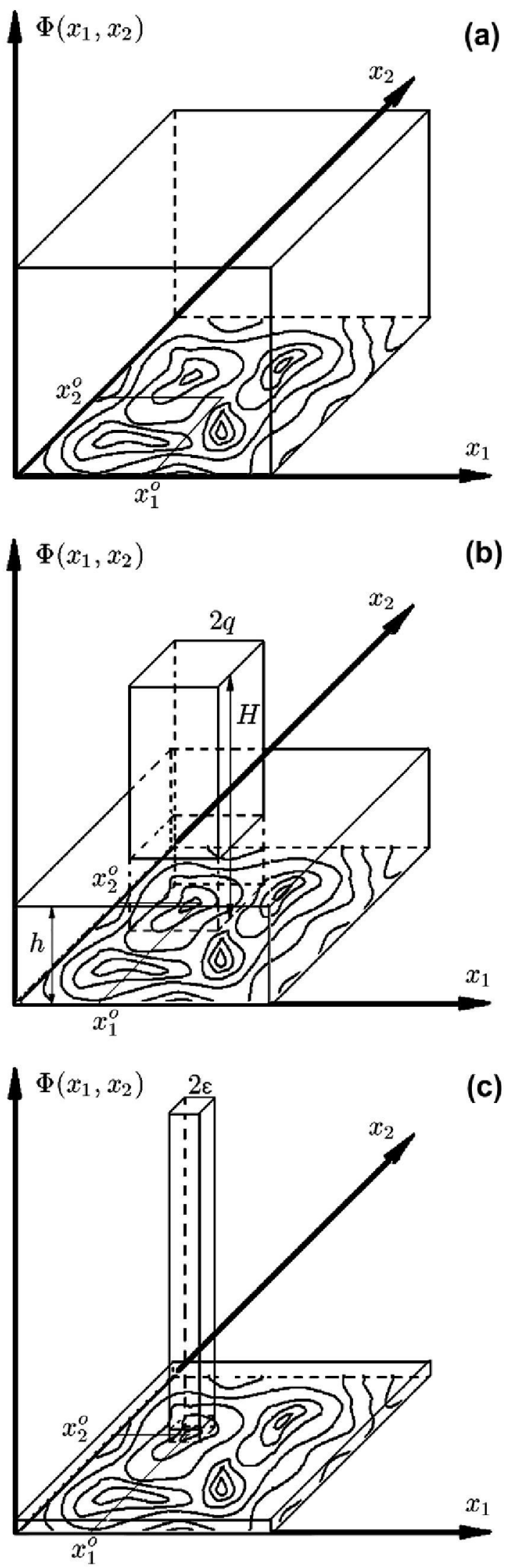

Fig. 1. The 2-dimensional pedestal frequency distribution transformations during the entire random search process: (a) shows the pedestal frequency distribution used for the first algorithm iteration; (b) shows the pedestal frequency distribution can be obtained in the middle of the search process; (c) shows the pedestal frequency distribution for the final algorithm iteration transformed to the $\delta$ function) (Abakarov et al., 2009a). 


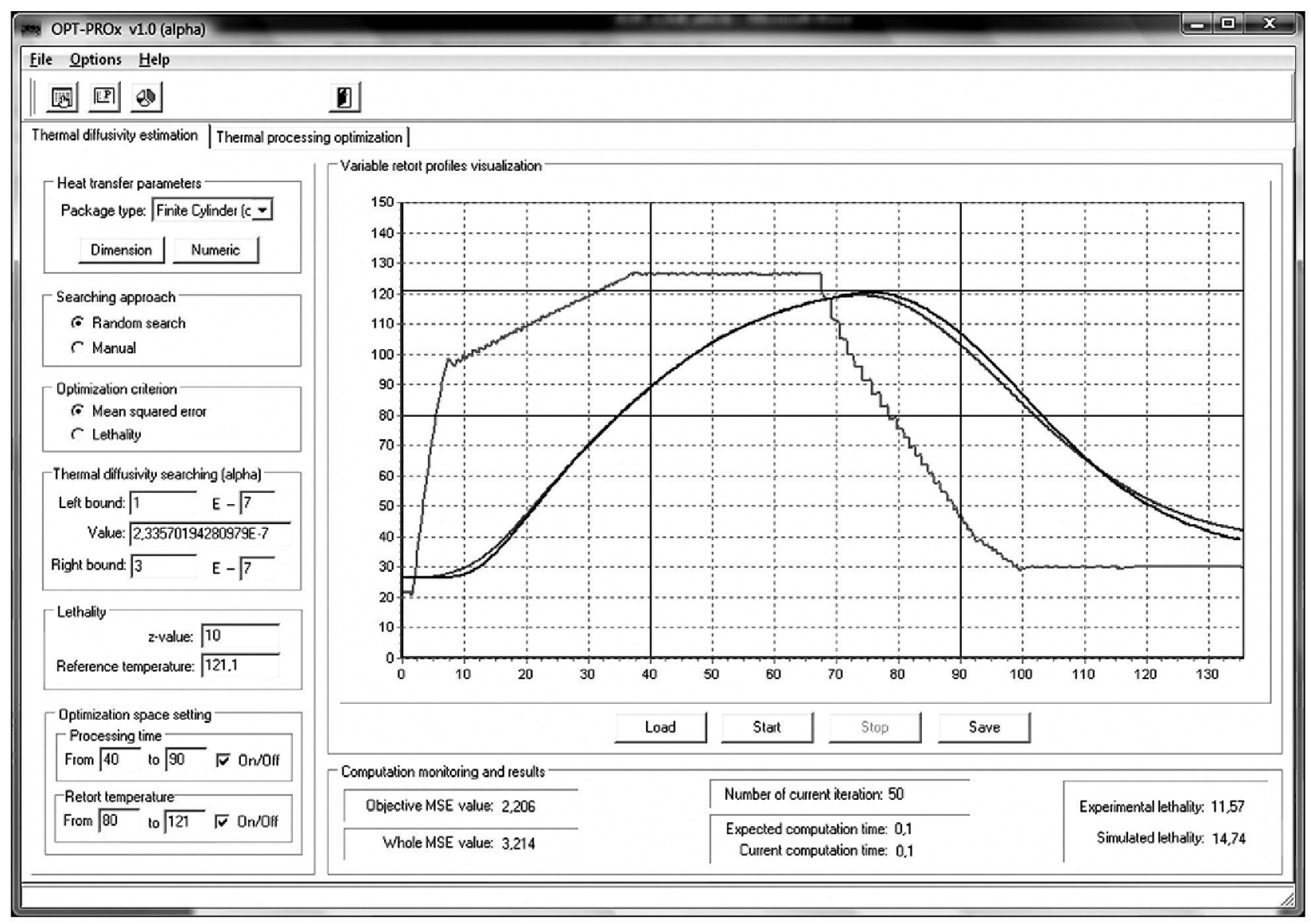

Fig. 2. Worksheet for determination of heat transfer coefficient.

variable, and $\Phi: \mathcal{R} \backslash \rightarrow \mathcal{R}$ is a continuous objective function. It is supposed, that all of the constraints are included in the objective function ( 30 ) by utilizing a penalty function approach (Himmelblau, 1972).

The adaptive random search method belongs to a specific class of global stochastic optimization algorithms (Zhigljavsky and Zilinskas, 2008). This class of algorithms is based on generating the decision variables from a given probability distribution, and the term "adaptive" consists of modifications to the probability distribution utilized in the searching process, which, throughout the whole search process, act as minimum computations of the objective function, locating global solutions (Tikhomirov, 2006; Abakarov et al., 2009a). A discrete analogue of the normal distribution - the pedestal probability distribution - is utilized in the adaptive random search algorithm. After every calculation of problem (1), the pedestal distribution of $x=\left\langle x_{1}, x_{2}, \ldots, x_{n}\right\rangle$ is modified so that the probability of finding the optimal value of the objective function is increased.

Let $I_{i} \subset X$ be a prospective interval for variable $x_{i}, i \in 1: n$ and $2 q$ be the width of each prospective interval. Let $I$ be a Cartesian product of sets $I_{i}, i \in 1: n$. For the random search algorithm $I$ is interpreted as a prospective sub-domain with center point $x_{i}^{0}, i \in 1: n$. It is assumed that the optimal solution of problem (30) always belongs to the prospective sub-domain $I$ with the probability not less than 0.5 (Tikhomirov, 2006). Thus, the procedure of the adaptive random method can be described as follows (Abakarov et al., 2009a):

(1) Set the total number of random search iterations Ns.

(2) Set the center point $x_{i}^{0}, i \in 1: n$, as the center point of the initial prospective sub-domain $I$.
(3) Generate a new value of vector $x^{s} \in X$ from the current pedestal probability distribution $F_{s}\left(x^{s-1}\right)$.

(4) Compute the value of the objective function $\Phi^{s}=\Phi\left(x^{s}\right)$ and calculate a minimal value of the objective function in step $s$ by using the formula

$\Phi_{\min }^{s}=\min \left\{\Phi^{s}, \Phi_{\min }^{s}\right\}$

(5) If $\Phi_{\min }^{s}<\Phi_{\min }^{s-1}$ set the center point $x^{0}=x^{5}$.

(6) Modify the pedestal probability distribution.

(7) $s:=s+1$.

(8) If $s<N_{s}$ then go to step 2.

(9) End.

In order to modify the pedestal probability distribution (step 5), the following formulas are used (Abakarov et al., 2009a):

- to calculate the probability density $h^{s}$ for $\operatorname{step} s, s \in 1: N_{s}$, the following formula is used:

$$
h^{s}=\frac{1-p^{s}}{1-v^{s}}
$$

where $v^{s}$ is the volume of prospective sub-domain of random search which we have in steps $\left(v^{0}=1\right)$ and $p^{s}$ is the assumed probability in steps where the optimal solution of problem (1) belongs to the prospective sub-domain $I$;

- to calculate current volume $v^{s}$ and assumed probability $p^{s}$, the basic random search method uses the following expressions: 


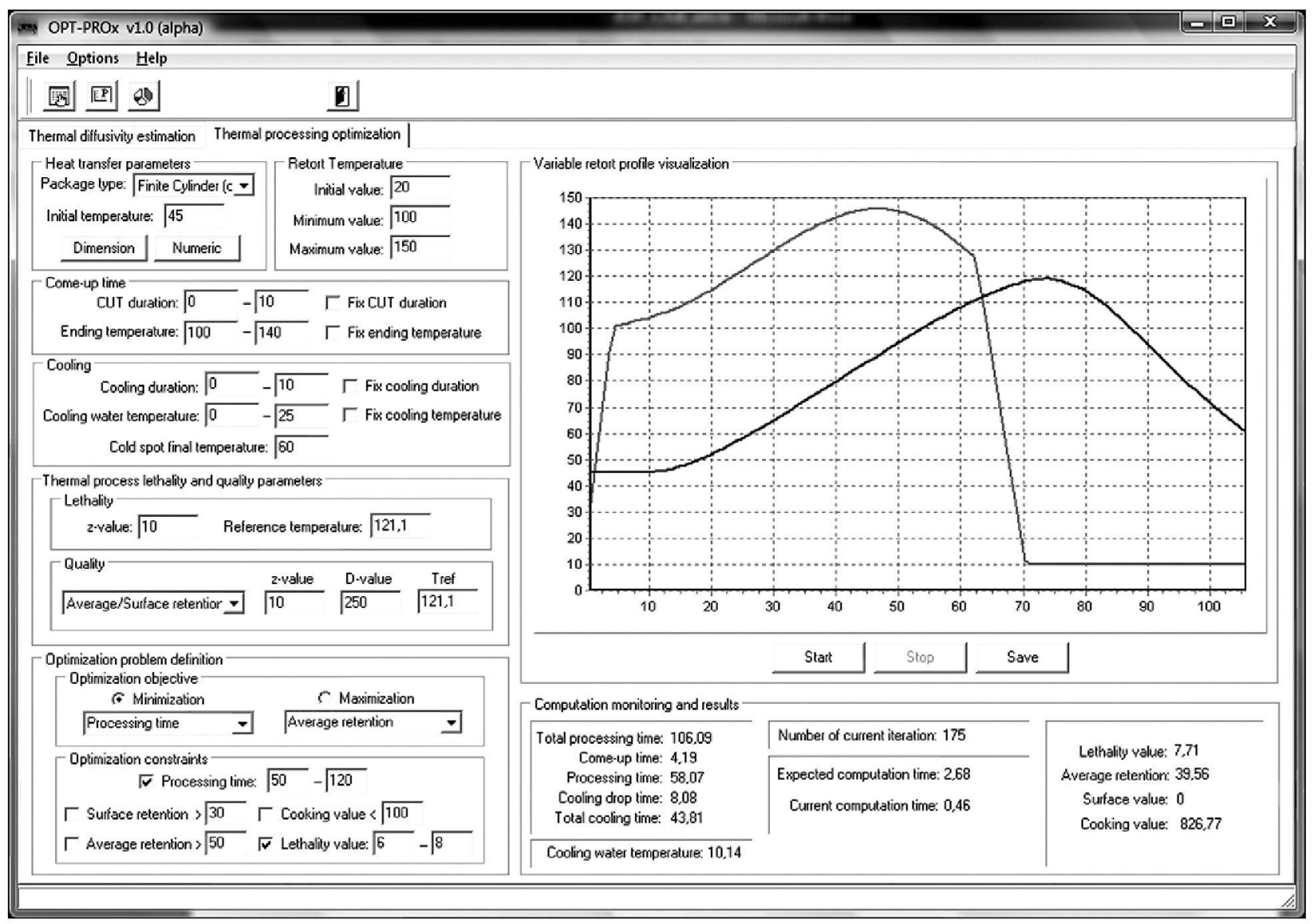

Fig. 3. Thermal food processing optimization worksheet.

Table 1

Parameters utilized in the thermal process simulation study (Erdogdu and Balaban, 2002; Simpson et al., 2008; Sendîn et al., 2010).

\begin{tabular}{llll}
\hline Product & Case study A & Case study B & Case study C \\
\hline & Pork pure & Tuna fish & - \\
\cline { 2 - 4 } Can & $307 \times 409$ & RO-1150 & Sphere \\
Diameter $(\mathrm{m})$ & 0.0875 & 0.15 & 0.032 \\
Height $(\mathrm{m})$ & 0.1160 & 0.07 & - \\
$\alpha\left(\mathrm{m}^{2} \mathrm{~s}^{-1}\right)$ & $1.5443 \times 10^{-7}$ & $1.143 \times 10^{-7}$ & $1.54 \times 10^{-7}$ \\
$T_{0}\left({ }^{\circ} \mathrm{C}\right)$ & 45 & 25 & 40 \\
Microorganism & Bacillus & Clostridium & Bacillus \\
& stearothermophilus & botulinum & stearothermophilus \\
\hline$z\left({ }^{\circ} \mathrm{C}\right)$ & 10 & 10 & 10 \\
$D_{\text {reff }}(\mathrm{s})$ & 240 & 15 & 240 \\
$T_{\text {reff }}(\mathrm{s})\left({ }^{\circ} \mathrm{C}\right)$ & 121.11 & 121.11 & 121.11 \\
Quality factor & Thiamine & Luminosity $(\mathrm{L}-$ & Thiamine \\
& & Hunter value $)$ & \\
\hline$z_{c}\left({ }^{\circ} \mathrm{C}\right)$ & 25.56 & 44.00 & 35.00 \\
$D_{\text {refc }}(\mathrm{s})$ & $10,716.0$ & $88,000.0$ & $10,716.0$ \\
$T_{\text {refc }}(\mathrm{s})\left({ }^{\circ} \mathrm{C}\right)$ & 121.11 & 121.11 & 121.11 \\
\hline
\end{tabular}

$q^{s+1}=q^{s}(2 \varepsilon)^{\frac{1}{N_{s}}}, \quad q^{0}=\frac{1}{2}$,

$v^{s}=\left(2 q^{s}\right)^{n}$

where $\varepsilon$ is the given accuracy;

$p^{s}= \begin{cases}\frac{s^{s}\left(p_{\min }-1\right)}{s_{\min }}+1, & \text { if } 0 \leqslant v^{s} \leqslant v_{\min } \\ \frac{v^{s}\left(1-p_{\min }\right)}{1-v_{\min }}+\frac{p_{\min }-v_{\min }}{1-v_{\min }}, & \text { if } v_{\min } \leqslant v^{s} \leqslant 1 .\end{cases}$
Variables $p_{\min }$ and $q_{\min }\left(v_{\min }=\left(q_{\min }\right)^{n}\right)$ are two heuristic parameters in the adaptive random search which allow tuning the algorithm to different types of problems in accordance with the known physical properties of the system under consideration.

To generate a new value of vector $x^{s} \in X$ from the current pedestal probability distribution (step 2 ), the following subroutine is used (Abakarov et al., 2009a).

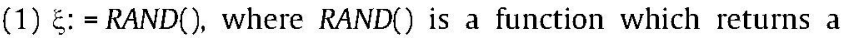
value uniformly distributed over $(0,1)$.

(2) For $i=1$ to $n$.

(3) If $\xi<h^{s}$ then $x_{i}^{s}=x_{\mathrm{r}}^{i}+\left(x_{\mathrm{r}}^{i}-x_{1}^{i}\right) \times R A N D\left(\right.$ ), where $a^{i}$ and $b^{i}$ are the left and right bounds, respectively, of decision variable $x_{i}$.

(4) Else $x_{i}^{s}=x_{i}^{0}-q+2 q \times R A N D()$.

(5) End If

(6) End For

During the search process, a random search generates random vector values $x^{0}, x^{1}, \ldots, x^{s}$, calculates problem (30), accumulates information about the solved problem and transforms the pedestal frequency distribution according to the computations performed. Transformations consist of reducing the deviation of the pedestal distribution (or prospective sub-domain $I \subseteq X$ ) around the mean (or the center point $x_{i}^{0}, i \in 1: n$ ), which is the current best solution $x^{0} \in X, f\left(x^{0}\right)<f\left(x^{j}\right), \forall j \in 1: s$. Fig. $1 \mathrm{~b}$ shows that the pedestal frequency distribution can be obtained in the middle of the search process, and now the points of domain $X$, in terms of probability density, can be divided into two non-overlapping subsets, where $h$ and $H$ are the probability densities of the non-prospective and the prospective sub-domains, respectively. Fig. 1c shows the pedestal frequency distribution for the final algorithm iteration trans- 


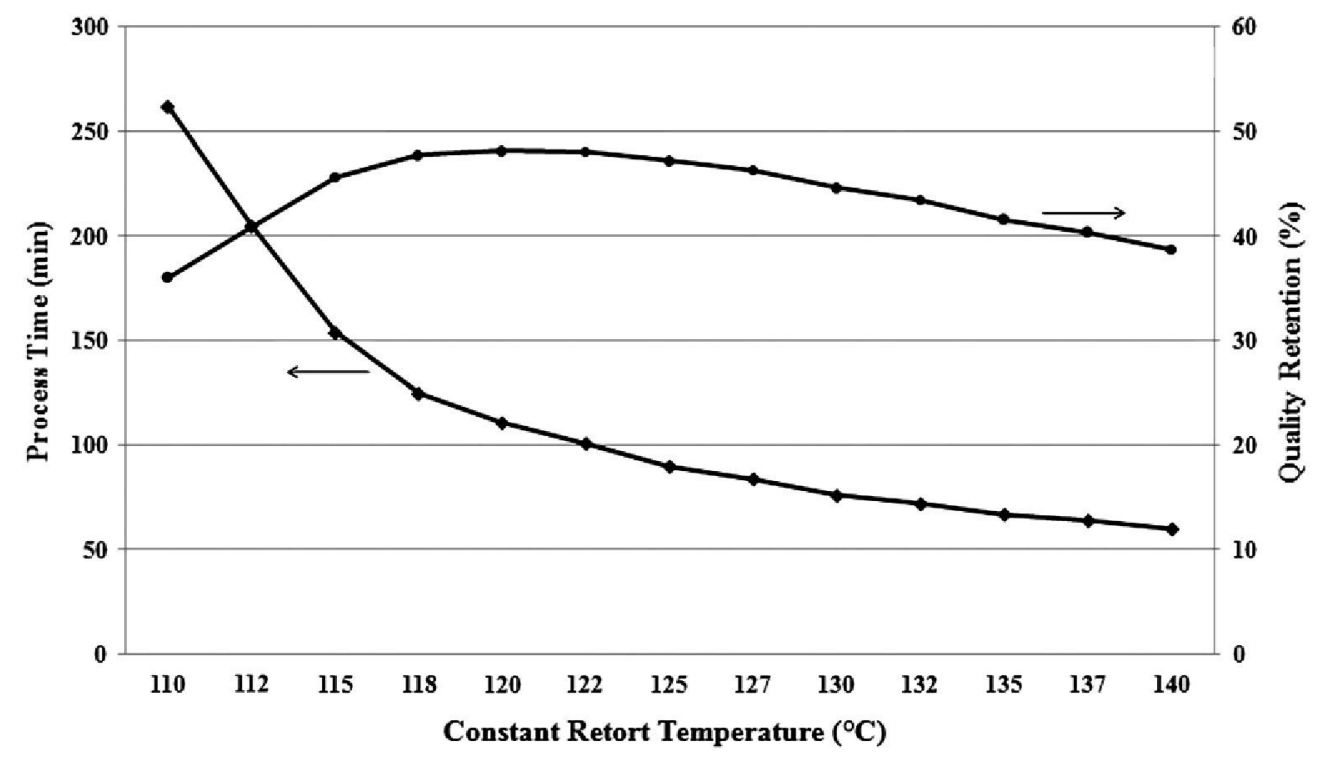

Fig. 4. Case study A: iso-lethality curve obtained for a target lethality of $F_{0}^{d}=12$, and curve showing thiamine retention as a function of equivalent CRT processes.

Table 2

Final quality (thiamine) retentions for each equivalent process.

\begin{tabular}{lll}
\hline CRT $\left({ }^{\circ} \mathrm{C}\right)$ & Time $(\mathrm{min})$ & Average quality (\%) \\
\hline 110 & 262 & 36.04 \\
112 & 205 & 40.96 \\
115 & 154 & 45.67 \\
118 & 125 & 47.76 \\
120 & 111 & 48.22 \\
122 & 101 & 48.11 \\
125 & 90 & 47.25 \\
127 & 84 & 46.36 \\
130 & 76 & 44.65 \\
132 & 72 & 43.47 \\
135 & 67 & 41.62 \\
137 & 64 & 40.42 \\
140 & 60 & 38.71 \\
VRT (1) & 88.4 & 48.22 \\
VRT $(2)$ & 111 & 50.85 \\
\hline
\end{tabular}

formed to the $\delta$-function, known as Dirac delta function (Hormander, 1983), and it is assumed that for any point $x^{\prime}$ of the final prospective sub-domain $I$, the following condition holds: $\left|x_{i}^{\prime}-x_{i}^{*}\right| \leqslant \varepsilon, \forall i \in 1: n$. In the sense of probability distribution, the Dirac delta function is the limit of a sequence of functions whose graphs become thin, tall peaks around the point $x^{\text {ast }}$ (Hormander, 1983).

\section{5. "OPT-PROx" software package}

Borland C++ Builder 6.0 was used to create the "OPT-PROX" GUI software. " "OPT-PROx" software contains two worksheets oriented to the numerical determination of heat transfer coefficient (Fig. 2), and to the thermal processing optimization (Fig. 3). The adaptive random search algorithm coupled with penalty functions approach, and the finite difference method with cubic spline approximation are utilized by "OPT-PROx" for simulation and optimization of the thermal food processes. The mean square error minimization principle is utilized in order to estimate the heat

1 "OPT-PROx" software is freely available at http://tomakechoice.com/optprox/ index.html. transfer coefficient of food to be processed under optimal condition.

The following types of objective functions and constraints are supported by "OPT-PROx" software. Types of objective functions:

- minimization of total processing time,

- minimization of cooking value,

- maximization of surface quality retention,

- maximization of average quality retention.

Optimization constraints for:

- surface quality retention,

- average quality retention,

- cook value,

- thermal lethality value,

- total thermal processing time.

The geometries supported by the "OPT-PROx" are the following:

- cylinder,

- rectangle,

- sphere.

The developed "OPT-PROx" graphic user interface allows the easy formulation of the required optimization problems through combining the mentioned above optimization objectives, constraints and geometries (Fig. 3).

\section{Results and discussions}

\subsection{Case study A: thermal processing under constant retort temperature profiles}

All numerical results presented in this research were obtained utilizing the "OPT-PROx" software package. Computations were performed on notebook with Intel, Triple-Core $\mathrm{CPU}, 2.40 \mathrm{GHz}$, 3.0 GB of RAM. As a first step, it was found all those combinations of constant retort temperature and processing time for the conditions listed in Table 1 that would deliver the same final target value of lethality (Sendín et al., 2010; Simpson et al., 2008). In this numerical experiment, a target lethality of $F_{0}^{d}=12 \mathrm{~min}$ was chosen to 


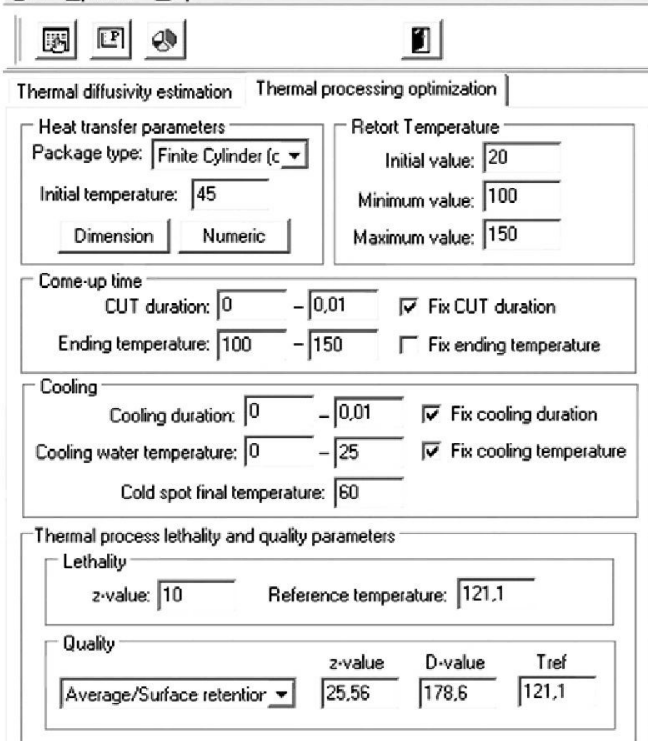

\begin{tabular}{|c|c|c|}
\hline \multicolumn{3}{|l|}{ [0ptimization problem defirition -} \\
\hline 6. Minimization & \multicolumn{2}{|l|}{$\Gamma$ Maximization } \\
\hline Processing time & Average retention & 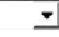 \\
\hline \multicolumn{3}{|l|}{ - Optimization constraints - } \\
\hline \multicolumn{3}{|c|}{$\nabla$ Processing time: $\sqrt{80}-\sqrt{111}$} \\
\hline$\Gamma$ sutlace retention $>\longdiv { 3 0 }$ & $\Gamma$ Cooking value $<1100$ & \\
\hline$\nabla$ Average retention $>\longdiv { 4 8 . 2 2 }$ & F Lethality value: 12 & $-\longdiv { 1 3 }$ \\
\hline
\end{tabular}
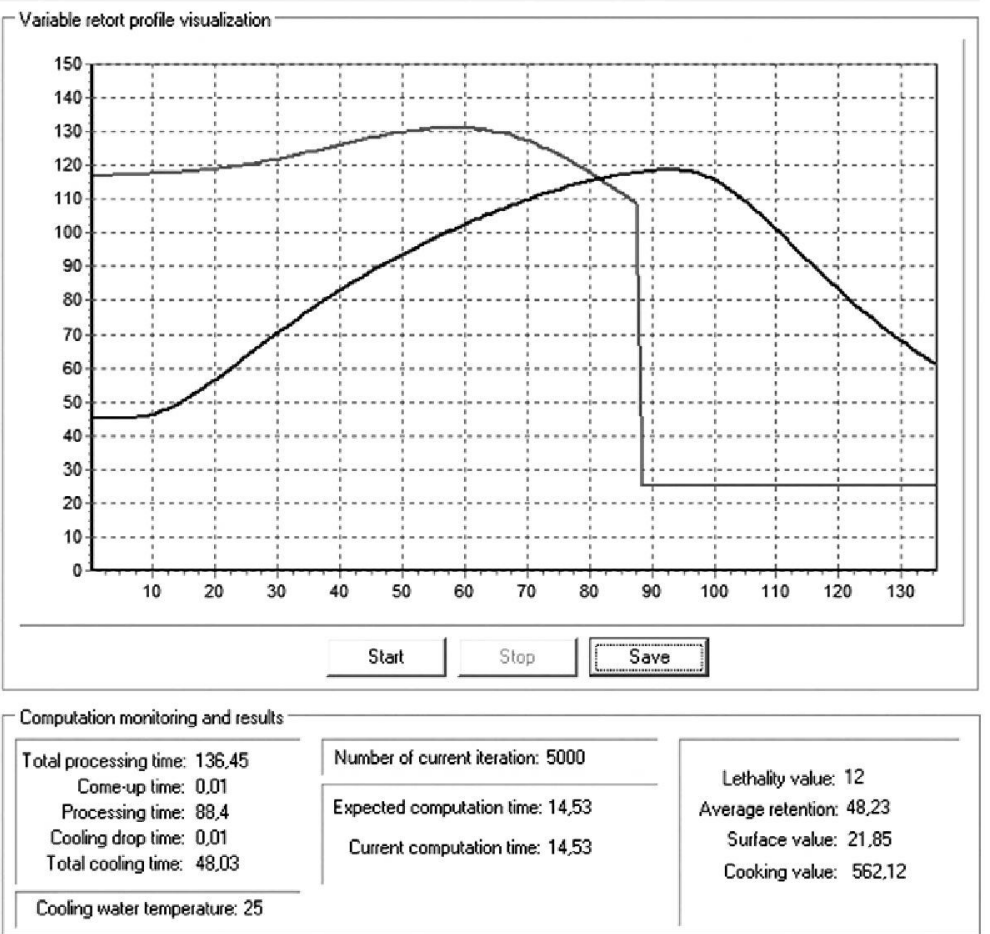

Lethality value: 12 Average retention: 48,23

Surface value: 21.85

Cooking value: 562,12

Cooling water temperature: 2

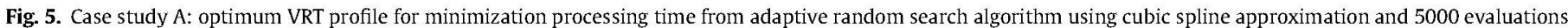
of objective function ("OPT-PROx" window).

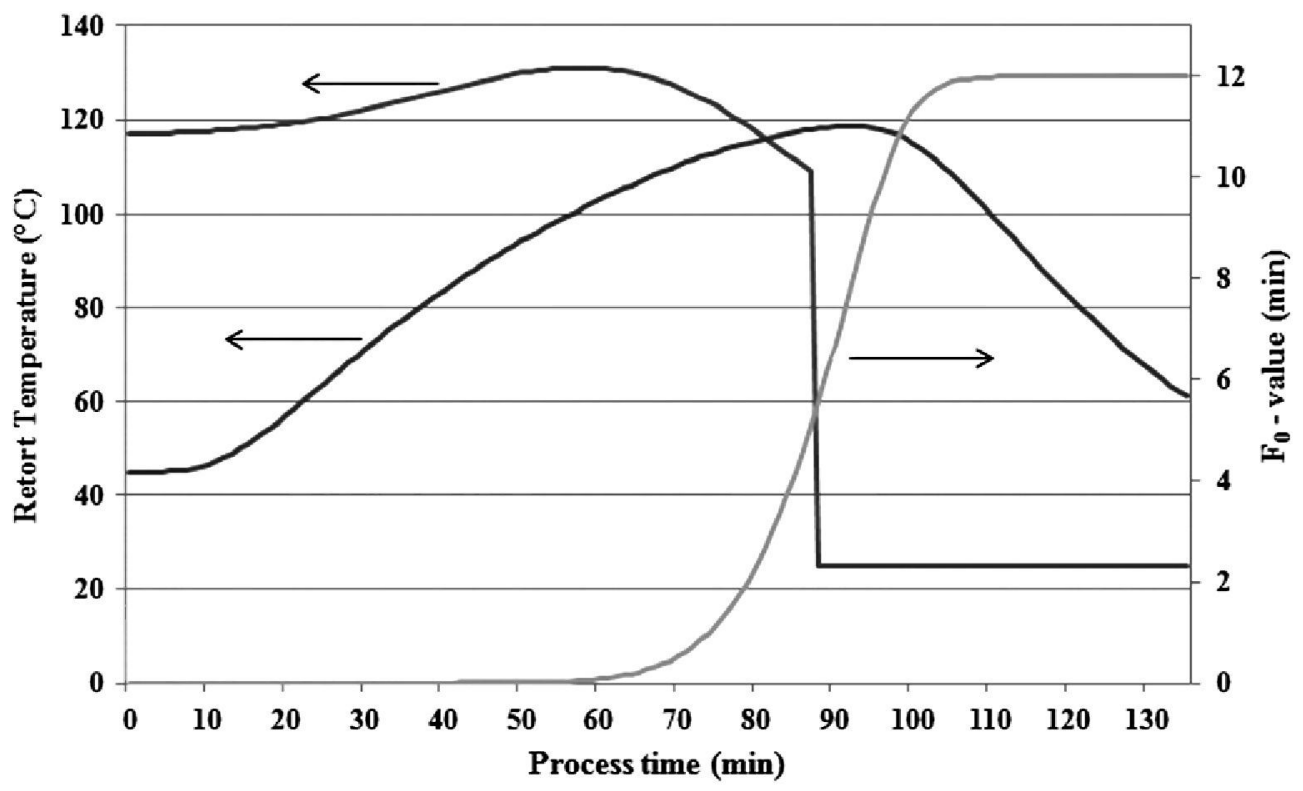

Fig. 6. Case study A: optimum VRT profile, resulting center temperature profile and accumulated lethality curve for minimization processing time problem.

produce the iso-lethality curve shown in Fig. 4. Each point on this curve defines a CRT and processing time resulting in a final target lethality. For each of these equivalent processes, the final level of quality (thiamine) retention $\overline{C(t)}$ was calculated, and presented as an optimization curve in Fig. 4 and Table 2.
We can see from Fig. 4 and Table 2 that the maximum level of thiamine retention possible with a constant retort temperature (CRT) was $48.22 \%$ over the range of possibilities, which could be as low as $36.04 \%$. The optimum CRT process for this product is one in which the retort temperature is held constant at $120^{\circ} \mathrm{C}$, 
OPT-PROx v1.0 (alpha)

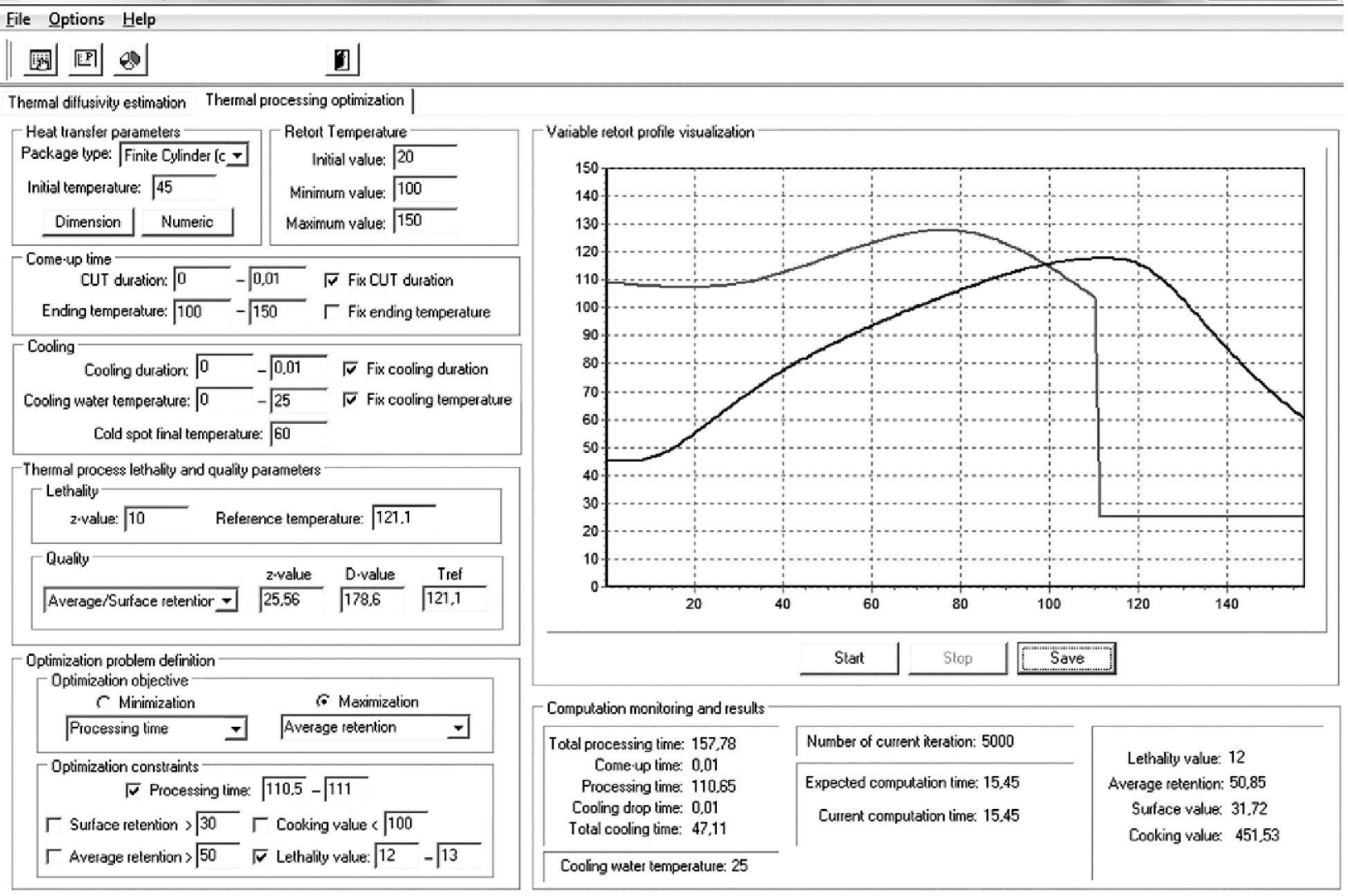

Fig. 7. Case study A: optimum VRT profile for maximum thiamine retention from adaptive random search algorithm and 5000 evaluations of objective function ("OPT-PROx" window).

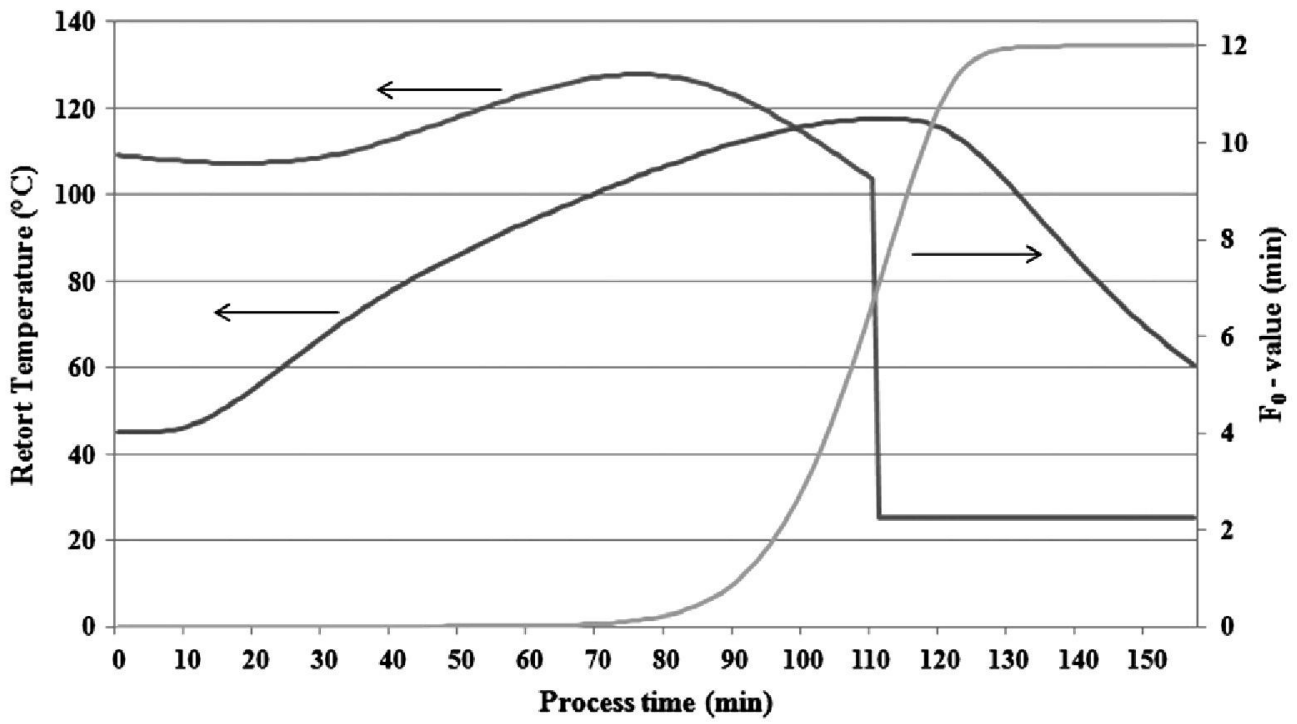

Fig. 8. Case study A: optimum VRT profile, resulting center temperature profile and accumulated lethality curve for maximum thiamine retention problem.

with a corresponding process time (time between steam on and off) of $111 \mathrm{~min}$.

\subsection{Case study A: Minimization processing time problem}

This numerical experiment deals with searching for the optimum VRT profile to minimize processing time within the constraints of assuring both minimum required target lethality and quality retention. Thus, the search routine was restricted in two ways, first to satisfy the lethality constraint of $F_{0}^{d}=12$ minutes, and secondly that the quality thiamine retention could not fall below $48.22 \%$. The result obtained by "OPT-PROx" with 5000 iterations of adaptive random search is shown in Figs. 5 and 6 and in Table 2 (see VRT(1)). The computation time spent by "OPT-PROx" 


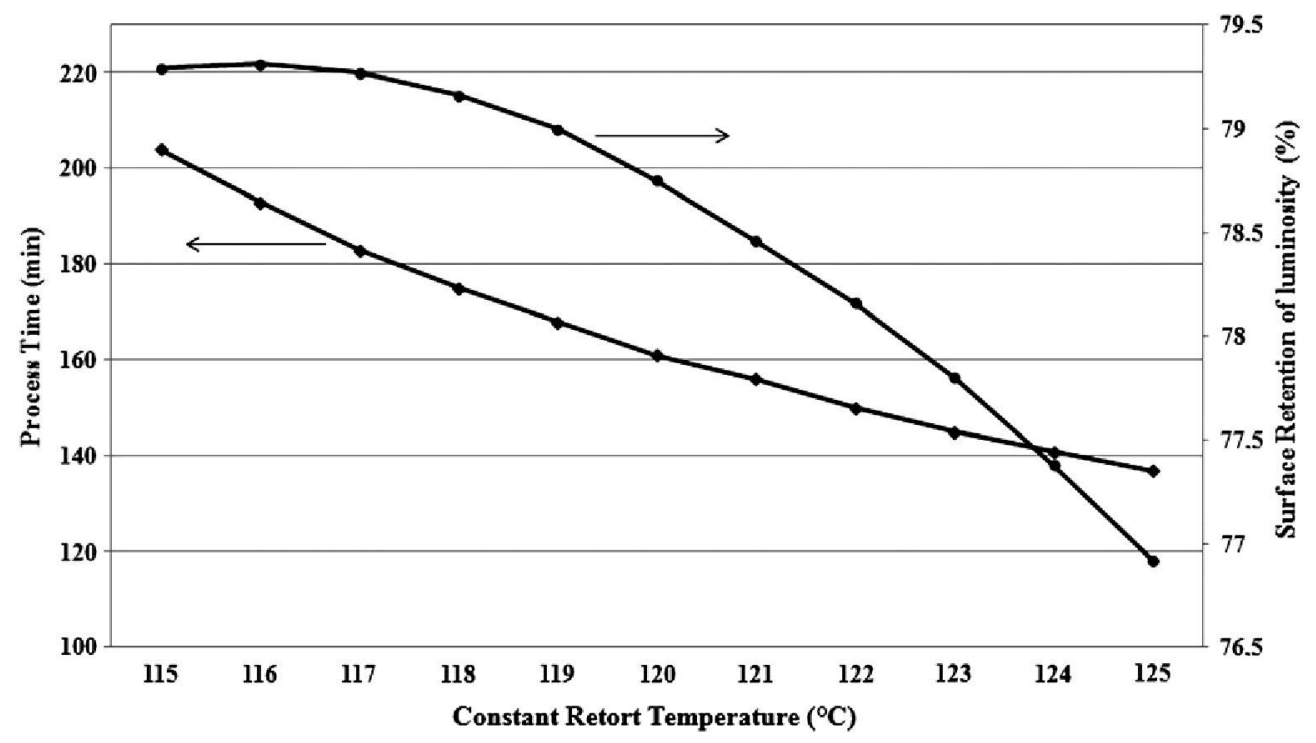

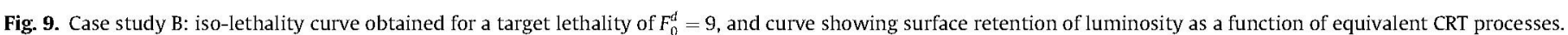

for the computation of optimal temperature profile was equal to $14.53 \mathrm{~min}$. In this case, the thiamine retention of $48.22 \%$ was achieved with a further reduction in processing time from $111 \mathrm{~min}$ down to $88.4 \mathrm{~min}$, thus the processing time was reduced on $12.47 \%$.

\subsection{Case study A: maximizing overall quality (nutrient) retention}

The numerical experiment was to see if any further improvement in thiamine retention would be possible with an optimum variable retort temperature profile within the upper and lower limits of retort temperature in the range of this study $\left(100-150^{\circ} \mathrm{C}\right)$ and for the processing time equal to $111 \mathrm{~min}$. The result, obtained with 5000 iterations of adaptive random search algorithm, shows that an optimum VRT process could further increase maximum thiamine retention only modestly to $50.85 \%$ from the $48.22 \%$ possible with the optimum CRT process (see Figs. 7 and 8 and Table 2, VRT(2)). The computation time spent by "OPT-PROx" for the computation of optimal temperature profile was equal to $15.45 \mathrm{~min}$. This result shows that little benefit was gained from increasing significantly the processing time from 88.4 to $111.0 \mathrm{~min}$, which is in accordance with the studies reported earlier (Teixeira et al., 1975; Banga et al., 1991; Durance, 1997; Abakarov et al., 2009b).

Table 3

Final levels of surface retentions (luminosity) for each equivalent process.

\begin{tabular}{lll}
\hline CRT $\left({ }^{\circ} \mathrm{C}\right)$ & Time (min) & Surface retention (luminosity) (\%) \\
\hline 115 & 204 & 79.29 \\
116 & 193 & 79.31 \\
117 & 183 & 79.27 \\
118 & 175 & 79.16 \\
119 & 168 & 79 \\
120 & 161 & 78.75 \\
121 & 156 & 78.46 \\
122 & 150 & 78.16 \\
123 & 145 & 77.8 \\
124 & 141 & 77.38 \\
125 & 137 & 76.92 \\
VRT $(3)$ & 148.1 & 80.0 \\
\hline
\end{tabular}

3.4. Case study B: thermal processing under constant retort temperature profiles

In this case study the thermal sterilization of canned tuna fish is considered (Sendin et al., 2010). As a first step, it was found all those combinations of constant retort temperature and processing time for the conditions listed in Table 1 that would deliver the same final target value of lethality. A target lethality of $F_{0}^{d}=$ $9 \mathrm{~min}$ was chosen to produce the iso-lethality curve shown in Fig. 9. For each of these equivalent processes, the final level of surface retention (luminosity) $S(t)$ was calculated, and presented as an optimization curve in Fig. 9 and Table 3. We can see from Fig. 9 and Table 3 that the variation in the surface retention of luminosity was relatively small (the maximum and minimum levels of surface retention were equal to $79.31 \%$ and $76.92 \%$, respectively), which is in accordance with the study reported earlier by Sendin et al. (2010). The optimum CRT process for this case is one in which the retort temperature is held constant at $116^{\circ} \mathrm{C}$, with a corresponding process time of $193.0 \mathrm{~min}$.

\subsection{Case study B: minimization processing time problem}

This numerical experiment deals with searching for the optimum VRT profile to minimize processing time within the constraints of assuring both minimum required target lethality and surface retention of luminosity. Thus, the search routine was restricted in two ways, first to satisfy the lethality constraint of $F_{0}^{d}=9 \mathrm{~min}$, and secondly that the surface retention of luminosity could not fall below $80.0 \%$. The result obtained by "OPT-PROX" with 5000 iterations of adaptive random search is shown in Figs. 10 and 11 and in Table 3 (see VRT(3)). The computation time spent by "OPT-PROx" software for the computation of optimal temperature profile was equal to $33.6 \mathrm{~min}$. In this case, the thiamine retention of $80.0 \%$ was achieved with a further reduction in processing time from $193.0 \mathrm{~min}$ down to $148.1 \mathrm{~min}$, thus the processing time was reduced on $23.3 \%$.

\subsection{Case study C: VRT optimization for spherical geometry}

This numerical experiment deals with searching for the optimum VRT profile to maximize surface quality (nutrient) retention 


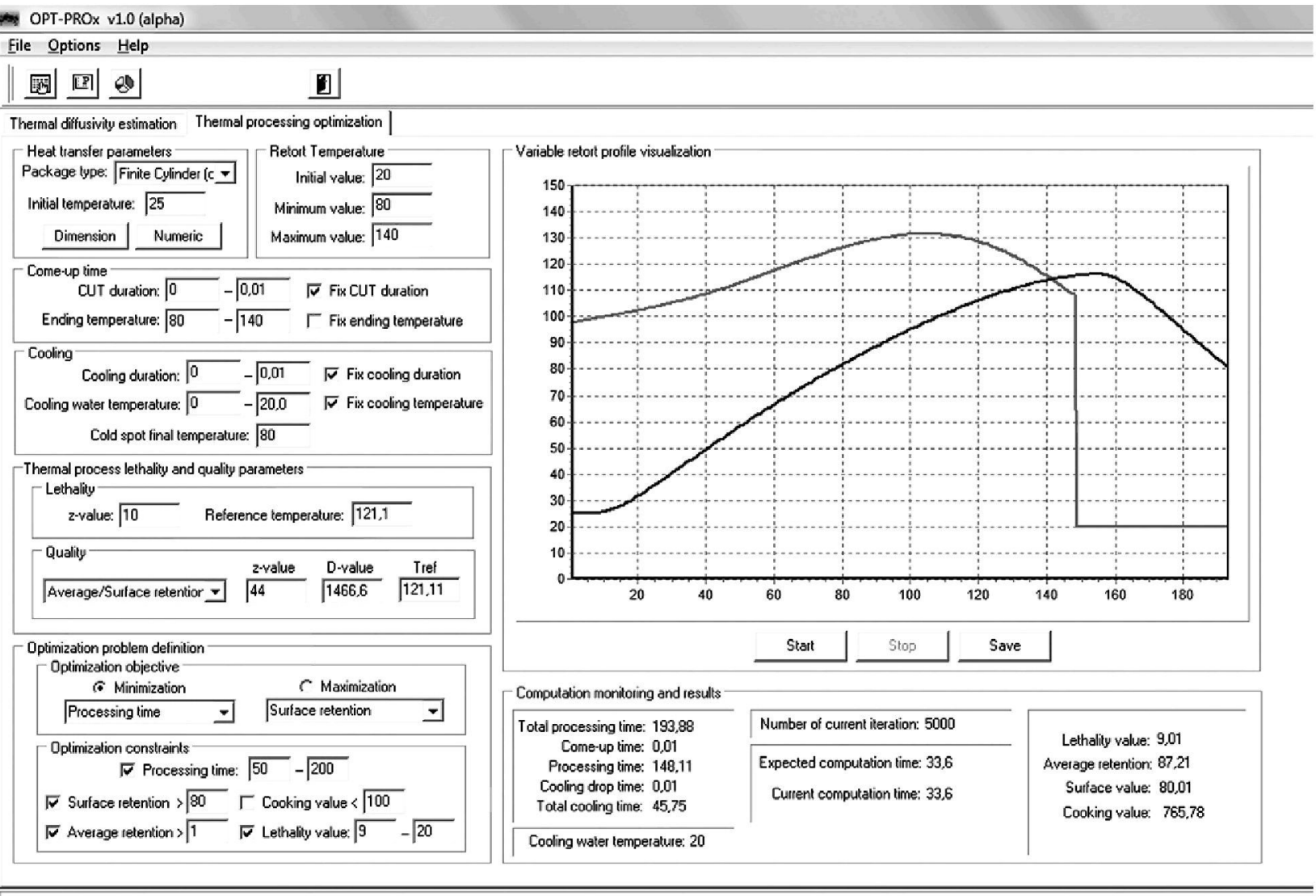

Fig. 10. Case study B: optimum VRT profile for minimization processing time from adaptive random search algorithm using cubic spline approximation and 5000 evaluations of objective function ("OPT-PROx" window).

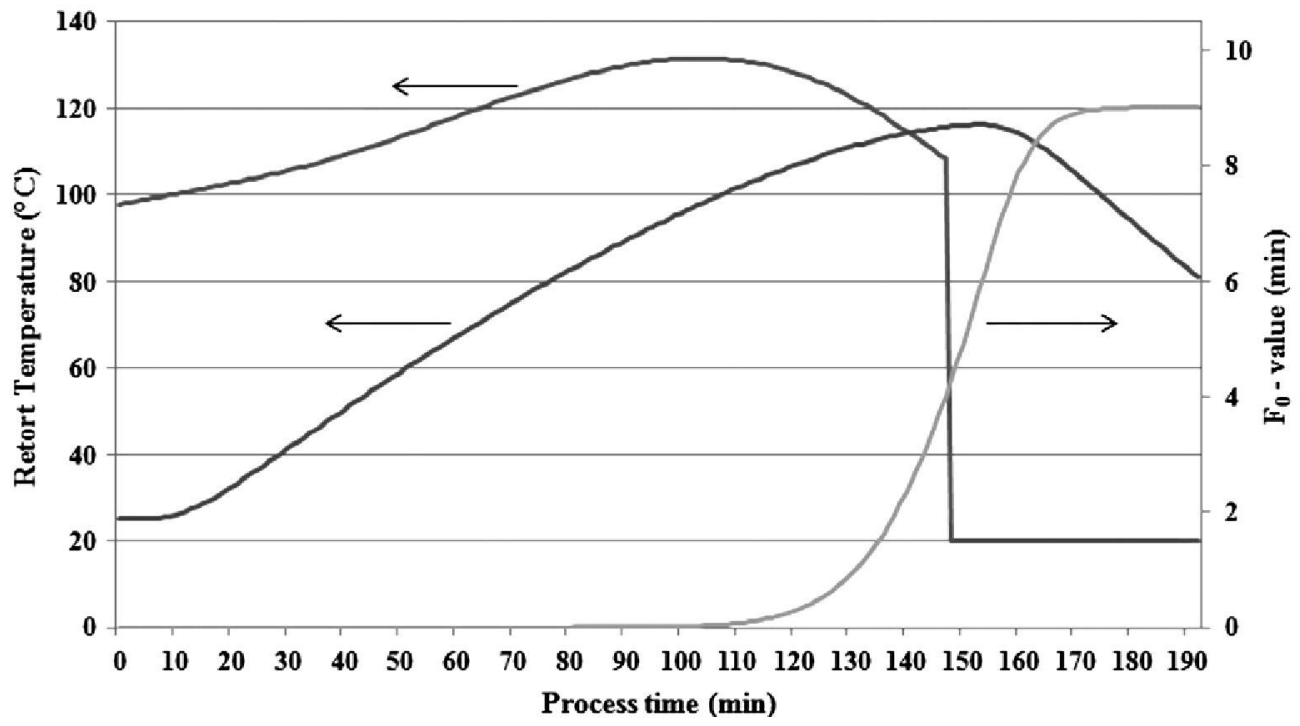

Fig. 11. Case study B: optimum VRT profile, resulting center temperature profile and accumulated lethality curve for minimization processing time problem.

for spherical geometry within the constraint of assuring minimum required target lethality $F_{0}^{d}$ equal to $9 \mathrm{~min}$. We also compare the optimization results obtained by "OPT-PROx" software with results found in literature by Noronha et al. (1993) and by (Erdogdu and Balaban, 2002), where the quasi-Newton multivariable and the Complex optimization algorithms were successfully applied. Thermal and physical properties for these studies are listed in Table 1 . The result obtained by "OPT-PROx" with 5000 iterations of adaptive random search is shown in Figs. 12 and 13. The computation time spent by "OPT-PROx" for the computation of optimal temperature profile was equal to $23.66 \mathrm{~min}$. The final surface thiamine retention was found to be $82.48 \%$ for this case, which is almost similar to the values $83.5 \%$ and $83.68 \%$, reported by Noronha et al. (1993) and by Erdogdu and Balaban (2002), respectively. The total processing time computed by "OPT-PROX" software was equal to $18.43 \mathrm{~min}$, which is very 


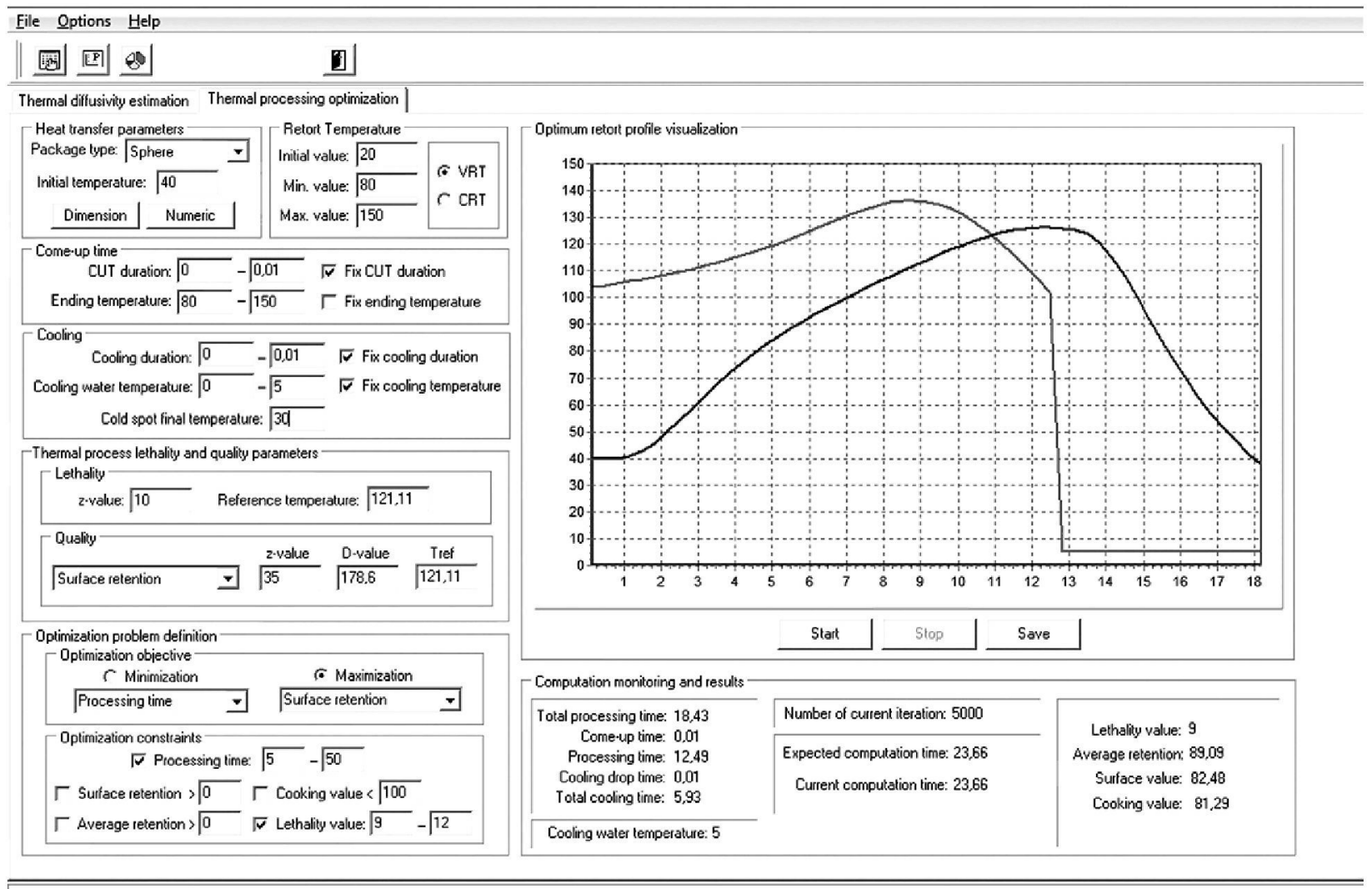

Fig. 12. Case study C: optimum VRT profile for maximum thiamine retention from adaptive random search algorithm and 5000 evaluations of objective function ("OPTPROx" window).

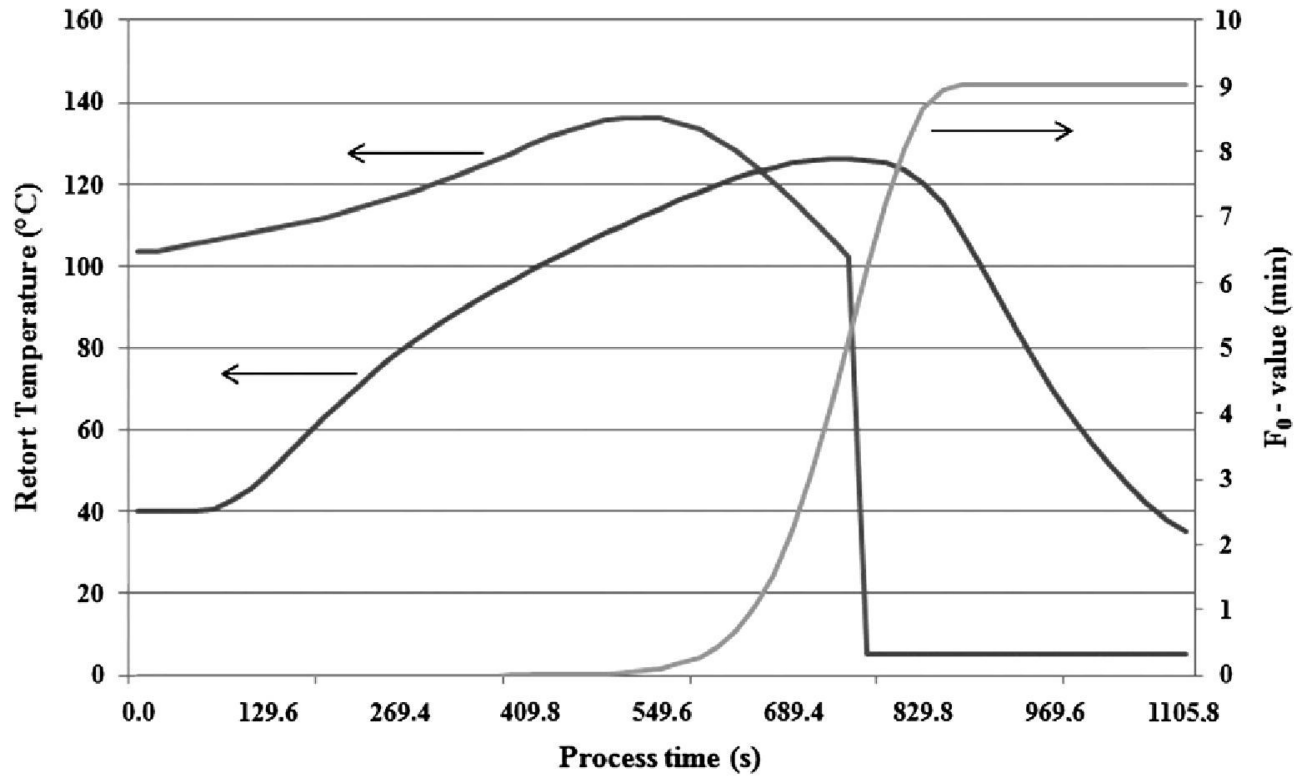

Fig. 13. Case study C: optimum VRT profile, resulting center temperature profile and accumulated lethality curve for maximum surface quality (nutrient) retention problem.

similar to the value 18.04 min reported by Erdogdu and Balaban (2002) (see Fig. 13).

\section{Conclusions and future direction}

Findings from this study would suggest that the developed user-friendly interfaces and the utilized numerical approaches make the simulation and optimization of the thermal food processing easy and adaptable. The "OPT-PROx" software is valuable to find the improvements in different objective functions for different geometrical shapes and for different processing conditions. The agreement between the computations performed by "OPTPROX" and the computation results obtained by other researches was consistently good under different processing conditions, 
which also demonstrate the reliability of the developed software. Therefore, we would suggest that the "OPT-PROx" software package can be useful to food scientists in research and education, as well as to engineers involved in optimization of thermal food processing. The possible direction for future research is to develop the version of "OPT-PROx" software, which will be able to tackle multi-criteria decision making problems arising in thermal processing of canned foods.

\section{Acknowledgment}

The author Alik Abakarov wishes to thank the MICINN (Ministerio de Ciencia e Innovación de España) with the project Smart-QC (GL2008-05267-C03-03), and the TAGRALIA-UPM, which is part of the CEI Moncloa Campus.

\section{References}

Abakarov, A., Sushkov, Yu., Almonacid, S, Simpson, R, 2009a. Multi-objective optimization based on adaptive random search method: optimization of food processing. Journal of Food Science 74 (9), E471-E487.

Abakarov, A., Sushkov, Yu., Almonacid, S., Simpson, R., 2009b. Thermal processing optimization through a modified adaptive random search. Journal of Food Engineering 93 (2), 200-209.

Abakarov, A., 2011. A multi-criteria decision making approach for food engineering. In: 11th International Congress on Engineering and Food, May 22-26, Athens (Greece), pp. 1525-1526.

Alonso, A., Arias-Mendez, A., Balsa-Canto, E., Garcia, M., Molina, J., Vilas, C., Villafin, M., 2011. Optimal on-line decision making for food thermal processes. In: 11th International Congress on Engineering and Food, May 22-26, Athens (Greece), pp. 281-282.

Almonacid-Merino, S.F., Simpson, R., Torres, J.A., 1993. Time-variable retort temperature profiles for cylindrical cans: Batch process time, energy consumption, and quality retention model. Journal of Food Process Engineering 16, 271-287.

Ansorena, M., Salvadori, V., 2011. Optimization of thermal processing of canned mussels. Food Science and Technology International 17 (5), 449-458.

Awuah, G., Ramaswamy, H., Economides, A., 2007. Thermal processing and quality: principles and overview. Chemical Engineering and Processing 46 , 584-602.

Balsa-Canto, E., Banga, J., 2010. AMIGO: A model identification toolbox based on global optimization. $\mathrm{CAB}$ (11th Computer Applications in Biotechnology), Leuven, Belgium.

Balsa-Canto, E., Banga, J., 2011. AMIGO, a toolbox for advanced model identification in systems biology using global optimization. Bioinformatics 27 (16), 2311 2313.

Banga, J., Balsa-Canto, E., Moles, C., Alonso, A., 2003. Improving food processing using modern optimization methods. Trends in Food Science and Technology 14 (4), 131-144.

Banga, J., Martín, R., Singh, P., 1994. ICRS/DS: a computer package for the optimization of batch processes and its applications in food processing. In: "Developments in Food Engineering", Part 2. Blackie Academic \& Professional, pp. $730-732$.

Banga, J., Perez-Martin, R., Gallardo, J., Casares, J., 1991. Optimization of thermal processing of conduction-heated canned foods: study of several objective functions. Journal of Food Engineering 14, 25-51.

Chazala, S., 1998. Sous Vide and Cook-Chill Processing for the Food Industry. Chapman \& Hall Food Science Book.

Chen, C., Ramaswamy, H., 2007. Visual Basics computer simulation package for thermal process calculations. Chemical Engineering and Processing 46, 603613.

Chen, C., Ramaswamy, H., 2002. Modeling and optimization of variable retort temperature (VRT) thermal processing using coupled neural networks and genetic algorithms. Journal of Food Engineering 53, 209-220.

Erdogdu, F., Balaban, M., Chau, K., 1998. Automation of heat transfer coefficient determination: development of a windows-based software tool. Food Technology in Turkey 10, 66-75.

Erdogdu, F., Balaban, M., Chau K., 1999. Thermal processing of shrimp: development of a windows-based software tool. In: Paper Presented at the IFT Annual Meeting, July 24-28, Chicago, IL.

Erdogdu, F., 2000. Simultaneous optimization of quality retention in conduction heated foods of different geometries. Ph.D. Dissertation, University of Florida, Gainesville, FI

Erdogdu, F., Balaban, M.O., 2002. Non-linear constrained optimization of thermal processing: I. development of a modified algorithm of complex method. Journal of Food Process Engineering 25 (1), 1-22.

Erdogdu, F., Balaban, M.O., 2003a. Complex method for non-linear constrained multi-criteria (multi-objective function) optimization of thermal processing. Journal of Food Process Engineering 26 (4), 357-375.

Erdogdu, F., Balaban, M., 2003b. Nonlinear constrained optimization of thermal processing II. Variable process temperature profiles to reduce process time and to improve nutrient retention in spherical and finite cylindrical geometries. Journal of Food Process Engineering 26 (3), 303-314.

Erdoğdu, F., 2008. Optimization in Food Engineering. CRC Press, New York, USA 2009, $758 \mathrm{p}$.

Durance, T., 1997. Improving canned food quality with variable retort temperature processes - review. Trends in Food Science and Technology 8 (4), 113-118.

Garcia, M.S.G., Balsa-Canto, E., Alonso, A.A., Banga, J.R., 2005. Computing optima operating policies for the food industry. Journal of Food Engineering $74(1), 13$ 23.

Halder, A., Dhall, A., Datta, A., Glenn Black, D., Davidson, P., Li, J., Zivanovic, S., 2011. A user-friendly general-purpose predictive software package for food safety. Journal of Food Engineering 104, 173-185.

Hayakawa, K., 1977. Mathematical methods for estimating proper therma processes and their computer implementation. Advanced Food Research 23, 75-141.

Hendrickx, M., Silva, C., Oliveira, F., Tobback, P., 1993. Generalized (semi)-empirical formulae for optimal sterilization temperatures of conduction-heated foods with infinite surface heat transfer coefficients. Journal of Food Engineering 19 (2), 141-158.

Himmelblau, D., 1972. Applied Nonlinear Programming. McGraw-Hill Book Company, New York.

Hormander, L., 1983. The analysis of linear partial differential operators I, Grund. Math. Wissenschaft., 256, Springer, MR0717035, ISBN 3-540-12104-8.

Hoffman, J., 2001. Numerical Methods for Engineers and Scientists - Second Edition. Marcel Dekker, Inc., New York.

Holdsworth, S., 1985. Optimization of thermal processing - a review. Journal of Food Engineering 4 (1985), 89-116.

Holdsworth, S., Simpson, R., 2007. Thermal Processing of Packaged Foods, second ed. Springer, New York, USA, p. 412.

Luikov, A., 1968. Analytical Heat Diffusion Theory. Department of Energy Engineering, University of Illinois, Illinois.

Lund, D., 1982. Applications of optimization in heat processing. Food Technology 36 (7), 97-100.

Lund, D., 1986. Kinetics of physical changes in foods. In: Okos, M.R. (Ed.), Physical and Chemical Properties of Food. American Society of Agricultural Engineers, St. Joseph, MI, pp. 367-381.

Mishkin, M., Karel, M., Saguy, I., 1982. Applications of optimization in food dehydration. Food Technology 36 (7), 101-109.

Mansfield, T., 1962. High temperature short time sterilization. In: Proceedings of First International Congress on Food Science and Technology, vol. 4. Gordon and Breach, London, p. 311.

Nakai, S., 1982. Comparison of optimisation techniques for application to food product and process development. Journal of Food Science 47 , 444-4152.

Newman, M., Holdsworth, S., 1989. Methods of thermal process calculation for food particles, Technical Memorandum, No. 321, Campden and Chorleywood Food Research Association, Chipping Campden.

Noronha, J., Hendrickx, M., Suys, J., Tobback, P., 1993. Optimization of surface quality retention during the thermal processing of conduction heated foods using variable temperature retort profiles. Journal of Food Processing Preservation $17,75-91$.

Noronha, J., Van Loey, A., Hendrickx, M., Tobback, P., 1996. Simultaneous optimisation of surface quality during the sterilisation of packed foods using constant and variable retort temperature profiles. Journal of Food Engineering 30, 283-297.

Ramaswamy, H., Marcotte, M., 2005. Food Processing: Principles and Applications Taylor \& Francis, Boca Raton, 2006, 420 p.

Sablani, S., Ramaswamy, H., 1995. Fluid to particle heat transfer coefficients in cans during end-over-end processing. Lebensmittel-Wissenschaft Technology 28 , 56-61.

Sendîn, J., Alonso, A., Banga, J., 2010. Efficient and robust multi-objective optimization of food processing: a novel approach with application to thermal sterilization. Journal of Food Engineering 98 (3), 317-324.

Sendín, J., Alonso, A., Banga, J., 2004. Efficient multi-criteria optimization of therma processing of foods. In: Proceedings of the "International Conference on Engineering and Food 9" (ICEF 9), March 7-11, Montpellier, France.

Sharma, S., Rangaiah, G., Cheah, K., 2011. Multi-objective optimization using MS Excel with an application to design of a falling-film evaporator system. Food and Bioproducts Processing. doi:10.1016/j.fbp. 2011.02.005

Silva, C., Hendrickx, M., Oliveira, F., Tobback, P., 1992. Critical evaluation of commonly used objective functions to optimize overall quality and nutrient retention of heat-preserved foods. Journal of Food Engineering 17 (4), 241258.

Silva, C., Oliveira, F., Hendrickx, M., 1994a. Quality optimization of conduction heating foods sterilized in different packages. International Journal of Food Science and Technology 29, 515-530.

Silva, C., Oliveira, F., Pereira, P., Hendrickx, M., 1994b. Optimum sterilization: comparative study between average and surface quality. Journal of Food Process Engineering 17, 155-176.

Simpson, R., Abakarov, A., Teixeira, A., 2008. Variable retort temperature optimization using adaptive random search techniques. Journal of Food Control 19 (11), 1023-1032.

Teixeira, A., Dixon, J., Zahradnik, J., Zinsmeister, G., 1969. Computer optimization of nutrient retention in the thermal processing of conduction heated foods. Food Technology $23,845-850$. 
Teixeira, A., Zinsmeister, G., Zahradnik, J., 1975. Computer simulation of variable retort control and container geometry as a possible means of improving thiamine retention in thermally-processed foods. Journal of Food Science 40 (3), $656-659$.

Teixeira, A., 1992. Thermal process calculations. In: Heldman, D.R., Lund, D.B. (Eds.), Handbook of Food Engineering. Marcel Dekker, Inc., New York, pp. 563-619.
Tikhomirov, A., 2006. On the Markov homogeneous optimization method computational. Mathematics and Mathematical Physics 46 (3), 361-375.

Wang, Y., Wig, T., Tang, J., Hallberg, L., 2003. Sterilization of foodstuffs using radio frequency heating. Journal of Food Science 68 (2), 539-544.

Zhigljavsky, A., Zilinskas, A., 2008. Stochastic Global Optimization. Ser. Springer Optimization and Its Applications, vol. 9. Springer-Verlag, Berlin, xvi+362 p. 